\title{
The effectiveness of a computer-assisted instruction programme on communication skills of medical specialists in oncology
}

\author{
Robert L Hulsman, ${ }^{1}$ Wynand $\mathcal{F} G$ Ros, ${ }^{2}$ facques $A M$ Winnubst $^{2}$ E Fozien M Bensing ${ }^{3,4}$
}

Background Although doctor-patient communication is important in health care, medical specialists are generally not well trained in communication skills. Conventional training programmes are generally time consuming and hard to fit into busy working schedules of medical specialists. A computer-assisted instruction (CAI) programme was developed - 'Interact-Cancer' which is a time-efficient learning method and easily accessible at the workplace.

Objective To investigate the effect of the CAI training, 'Interact-Cancer', on the communication behaviour of medical specialists, and on satisfaction of patients about their physician interaction.

Design Consultations of medical specialists with cancer outpatients were videotaped at 4 specific stages, 2 before and 2 after Interact-Cancer, with intervals of 4 weeks.

Patients/participants Participants were 21 medical specialists, mainly internists, working in 7 hospitals, and 385 cancer outpatients.

Methods Communication behaviour was assessed on 23 observation categories derived from the course content.
Frequencies were rated as well as judgements about the quality of the performance of each target skill. Satisfaction was measured by the Medical Interview Satisfaction Scale. Data were analyzed by means of multilevel statistical methods.

Results The behavioural assessment showed course effects on ratings of the physicians' quality of performance. No course effects were found on the frequencies of physicians' behaviours and on the patient satisfaction ratings.

Conclusions CAI is a promising method to supply medical specialists with postgraduate training of communication skills. The application of judgement ratings of communication behaviour proved to be valuable to evaluate course effects in real-life patient encounters.

Keywords ${ }^{\star}$ Computer-assisted instruction; physicianpatient relations; communication; education, medical, graduate/*methods; medical oncology $/{ }^{\star}$ education.

Medical Education 2002;36:125-134

\section{Introduction}

Doctor-patient communication is one of the most important tools in health care. Adequate interviewing techniques may lead the doctor to recognize the patient's problems and the patient to understand the doctor's instructions. ${ }^{1}$ Furthermore, adequate communication is

\footnotetext{
${ }^{1}$ Academic Medical Centre, Medical Psychology, Amsterdam ${ }^{2}$ Utrecht University, Faculty of Medicine, ${ }^{3}$ Utrecht University, Faculty of Social Sciences, ${ }^{4}$ NIVEL, Netherlands institute of primary health care

Correspondence: R L Hulsman, Academic Medical Centre, Department Medical Psychology, J4, PO Box 22660, 1100 DD Amsterdam, the Netherlands. Tel.: 003120566 4661; Fax: 003120566 9104; E-mail: R.L.Hulsman@AMC.UVA.NL
}

crucial to increase patient satisfaction. ${ }^{2,3}$ Problems in communication are often related to differences in expertise and perspectives of physicians and patients. While the physician generally regards health problems from a biomedical perspective, for the patient a disease is never a purely medical problem, but intrinsically connected to psychological, social and emotional concerns. ${ }^{1,4}$ In particular, diseases such as cancer can provoke uncertainty and considerable psychological distress in the patient, which often remain unnoticed due to the physicians' interviewing techniques. ${ }^{1,5}$ Physicians can learn to attend to patient concerns and to provide the patient with more adequate care and support by acquiring patient-centred communication skills. ${ }^{1,4,6}$

Despite the importance of doctor-patient communication, medical specialists receive very little education 


\section{Key learning points}

Computer-assisted instruction is a promising method to supply medical specialists with postgraduate training of communication skills.

CAI proved to have positive effects on the quality of the physician's communication skills as assessed by independent raters.

The physician's intention to change his/her behaviour is an important factor in establishing behavioural changes.

Judgement ratings about the quality of behaviour are a valuable extension to the commonly used frequency ratings in the assessment of communication behaviour.

in communication skills. In medical schools less than $2 \%$ of curricular time is spent on formal communication skills training. ${ }^{7,8}$ During the residential years, education is even more focused on acquiring specific medical and diagnostic skills at the expense of further development of communication skills. ${ }^{9}$

Continuing professional development of communication skills for practising physicians is needed. However, conventional training programmes are time-consuming, which may have a negative impact on physicians' interest in studying communication skills, ${ }^{2,10}$ as such programmes require participants to take days off, spend time travelling, or adapt their daily programme to pre-planned sessions, all of which interfere considerably with busy schedules.

Our study aims to minimise these objections by developing an easily accessible training programme by means of computer-assisted instruction (CAI). CAI is a flexible and time-efficient learning method, which puts the learner in control over his or her own learning process. It can be followed individually, anytime, anyplace, and at the learner's own pace. ${ }^{10,11}$ Modern CAI programmes have become dynamic learning tools in which the learner plays an active role. ${ }^{13}$ Due to the use of multimedia (text, pictures, sound and video) CAI applications can be presented in a lively and attractive way. ${ }^{14}$

Literature reviews of evaluation studies show that CAI is an effective and time-efficient learning method in a wide range of contexts. ${ }^{11,15}$ However, research on the effectiveness of CAI courses on communication skills is scarce and shows mixed results. ${ }^{12,16-18}$ Positive effects are found in studies which use only cognitive evaluation methods, focusing on knowledge and attitudes. ${ }^{12,17,18}$
However, improved knowledge or attitudes are not a sufficient condition for actual behavioural changes in daily practice. ${ }^{19}$ In the only study where observations of actual communication behaviour were included, no conclusions about the effectiveness of CAI could be drawn, due to the lack of a pre-test. ${ }^{16}$

In our study, a CAI course was developed on communication skills of medical specialists in oncology. The effectiveness of the CAI course 'Interact-Cancer' was evaluated in daily practice by assessing the participating physicians' communication behaviour in encounters with real patients.

The main research question is whether medical specialists can improve their actual communication behaviour as a result of a computer-assisted instruction programme. The second question is whether the patients become more satisfied with the interaction with their physician. The evaluation of the feasibility of the course and of the participants' opinion about the course is described elsewhere. ${ }^{20}$

\section{Methods}

\section{The CAl course 'Interact-Cancer'}

'Interact-Cancer' consists of four modules, in which various communication skills and techniques are presented, based on the principles of patient-centred medicine. ${ }^{4}$ The first module focuses on basic communication skills regarding verbal and non-verbal behaviour of physician and patient, such as eye contact, posture, facial expressions, tone of speech, and implicit and explicit ways of communication. The second module is concerned with breaking bad news with a focus on timing and phrasing; relieving patient's emotions; and discussing intended treatments while not overloading the patient. The third module deals with providing information effectively, based on two-way interaction, and checking the patient's needs. In addition, skills are presented which aim to enhance the effectiveness of information, such as repeating information and checking the patient's understanding and pre-existing knowledge. The fourth module is concerned with how to deal with patients' emotions, such as anxiety, uncertainty, depression and aggression in different stages of the illness: diagnosis, treatment, control, and palliative phases.

In each module, video examples are presented of poor and adequate communication in consultations of a surgeon with cancer patients. The first three modules are centred around the case of a breast cancer patient. In the fourth module on patient emotions, six different cases are presented on video. Communication theory 
and instructions about the displayed skills, including suggestions for improved communication behaviours, are presented verbally, visually supported by keywords. Multiple-choice practice questions about the video examples are presented frequently, followed by immediate feedback.

The operation of the programme is user-friendly and aimed at flexible use in a working environment. Operating instructions are presented in a menu on the monitor. Sections of each module can be easily repeated. The programme can be interrupted and resumed again at the same point. Each module can be completed within an hour. ${ }^{20}$

\section{Research design and procedures}

Measurements were performed at four specific stages at intervals of four weeks. Each measuring stage lasted for two weeks, therefore each physician participated in at least 20 weeks in the study. Base-line measurements were performed at $\mathrm{T} 1$. The interval between $\mathrm{T} 1$ and $\mathrm{T} 2$ is regarded as a control period, which provides information about possible changes in communication behaviour in the absence of an intervention. The course was presented in the intervention period between $\mathrm{T} 2$ and $\mathrm{T} 3$. The follow-up period between $\mathrm{T} 3$ and $\mathrm{T} 4$ provides information about the development of course effects over time; whether effects occur immediate at T3, are preserved at $\mathrm{T} 4$, or occur delayed at $\mathrm{T} 4$.

The effectiveness of the CAI course was evaluated by analyzing video recordings of real interactions with physicians and outpatients. The physicians recruited the cancer patients during their morning or afternoon consulting hours. Before each consultation, patients gave their written informed consent for the recording. Patients were then sent a questionnaire which was returned directly to the researcher after completion.

An important aspect in the establishment of a course effect on actual performance is the physicians' motivation to change their behaviour. ${ }^{19}$ Better-motivated physicians presumably accomplish more changes in their behaviour. Therefore, after the course and before the start of T3 the physicians were asked whether they had actually changed their behaviour. ${ }^{20}$ Those who reported actual changes will be indicated as implementers', otherwise they are 'non-implementers'.

\section{Physician sample}

The participants were 21 physicians from 7 hospitals, working in 6 different medical disciplines: 12 internists, 3 surgeons, 2 radiotherapists, 2 lung specialists, 1 gynaecologist and 1 urologist. All physicians were male, with an average age of $45 \cdot 4$ (SD $7 \cdot 7$ ), ranging between 34 and 58 . Their average number of years of experience was $18 \cdot 3$ (SD 8.3) ranging from 8 to 33 . Physicians were recruited for participation by approaching the chairmen of the oncology boards at 37 hospitals in the Netherlands. Twenty-three chairmen were interested in the study and wanted additional information. In 9 hospitals the minimum target of at least three participants per hospital could be achieved. This minimum was requested for reasons of efficiency in time and resources. Originally, 29 physicians completed the course and all measurements. In selecting consultations for statistical analysis, data from 8 physicians appeared unsuitable due to defective recordings or insufficient number (less than 2) of recordings of follow-up encounters per measuring stage.

Eight physicians $(38 \%)$ indicated after the course that they were indeed putting some of the skills taught into practice ('implementers'). The other 13 physicians ('nonimplementers') responded that they were not doing so, or were uncertain. The 8 implementers were 5 internists, 1 surgeon, 1 radiotherapist and 1 lung specialist. The nonimplementers were 7 internists, 2 surgeons, 1 radiotherapist, 1 lung specialist, 1 gynaecologist and 1 urologist. Both groups did not differ with regard to their average age, which was $45 \cdot 2$ (SD $7 \cdot 2$ ) vs. $45 \cdot 4$ (SD 8.2). The implementing physicians had 15.2 (SD 7.8) years of experience, whereas the other group had 19.9 (SD 8.4) years of experience (not significant).

\section{Patient sample}

The participating physicians were responsible for 676 oncological outpatients. Each patient was recorded only once. From these recordings, 385 consultations were selected consecutively for analysis. The number of selected patients at each measuring stage was: 94, 96, 95 and 100, respectively. Selection was based on three criteria: technical quality of the recording, type of encounter (only follow-up encounters were included), and the availability of a patient questionnaire. The number of patient encounters analyzed was limited to 5 per physician per measuring stage in order to have approximately the same number of consultations per physician. A complete data set of 5 consultations each measuring stage was available for 11 physicians. For the remaining physicians the number of analyzed consultations per measuring stage ranged between 2 and 5 .

Approximately two thirds of the 385 patients was female $(61 \cdot 3 \%)$. The average age of the patients was $58 \cdot 3$ (SD 13.0). The male patients (60.1, SD 14.2) were significantly older than the female patients $(57 \cdot 2, \mathrm{SD}$ 
12.1). No differences were found between the patient samples in the 4 measuring stages.

\section{Instruments}

Two sources of information about the quality of doctorpatient communication in the recorded consultations were applied: (1) independent behavioural observations (2) satisfaction of the patients about the interaction with their physicians.

Source 1: An independent assessment of the communication behaviour of the participating specialists was obtained by rating the video recordings of the consultations with the Communication Rating System (CRS), which was developed for this purpose. ${ }^{21}$ The CRS consists of 23 case-independent observation categories, which relate to 7 groups of skills: questions, information behaviours, information effectiveness enhancing behaviours, receptive behaviours, attending to feelings, negative behaviours and nonverbal behaviours (Table 1).

The observation method of the CRS is based on the $\mathrm{UCAM}^{22}$ and consists of 2 phases (Fig. 1). The first phase is the description phase which is dedicated to the observation of the physicians' behaviour and the registration of the frequency of occurrence of each obser- vation category. Nonverbal behaviour is rated both when the physician talks and when he listens to the patient. The unit of observation is each turn-of-speech, ranging from a single word to several sentences.

Describing the communication only by frequencies of communication behaviours has its limitations in providing a full picture of the adequacy of performance. ${ }^{23}$ What is lost, for example, is information about the context in which the behaviours took place, including: the topic under discussion, the timing of a technique, the extent to which patient and physician know each other, patient characteristics, etc. Therefore, in the second phase judgement ratings are assigned to each observation category concerning: (1) the frequency (quantity) of use of the communication behaviours (poor, good), and (2) the quality of the performance of each type of behaviour (poor, sufficient, good). Overall case scores were calculated for the quantity and quality ratings separately by averaging the scores on each item for each case. Also a general rating of the overall performance is assigned, on a 10-point scale. These judgement ratings in particular provide an opportunity to rate physician behaviours from a patient-centred perspective.

To prevent a 'halo effect', all consultations from different measuring stages were rated in a randomized

\begin{tabular}{|c|c|}
\hline Questions & Receptive behaviours \\
\hline $\begin{array}{l}\text { Open-ended questions } \\
\text { Closed questions } \\
\text { Asking for clarification }\end{array}$ & $\begin{array}{l}\text { Using silence } \\
\text { Stimulating patient participation } \\
\text { Attending to life-world } \\
\text { Paraphrasing }\end{array}$ \\
\hline Information behaviours & Attending to feelings \\
\hline $\begin{array}{l}\text { Providing information and advice } \\
\text { Answering explicit questions } \\
\text { Answering implicit questions }\end{array}$ & $\begin{array}{l}\text { Labelling feelings (reflecting) } \\
\text { Discussing feelings }\end{array}$ \\
\hline Enhancing information effectiveness & Negative behaviours \\
\hline $\begin{array}{l}\text { Checking pre-existing knowledge } \\
\text { Checking understanding } \\
\text { Repeating information } \\
\text { Summarizing }\end{array}$ & $\begin{array}{l}\text { Softening bad-news } \\
\text { Delay of bad-news } \\
\text { Using jargon } \\
\text { Interrupting } \\
\text { Incoherent continuations }\end{array}$ \\
\hline
\end{tabular}

Nonverbal behaviour

Table 1 Observation categories of the Communication Rating System (CRS)

Posture

Eye contact 


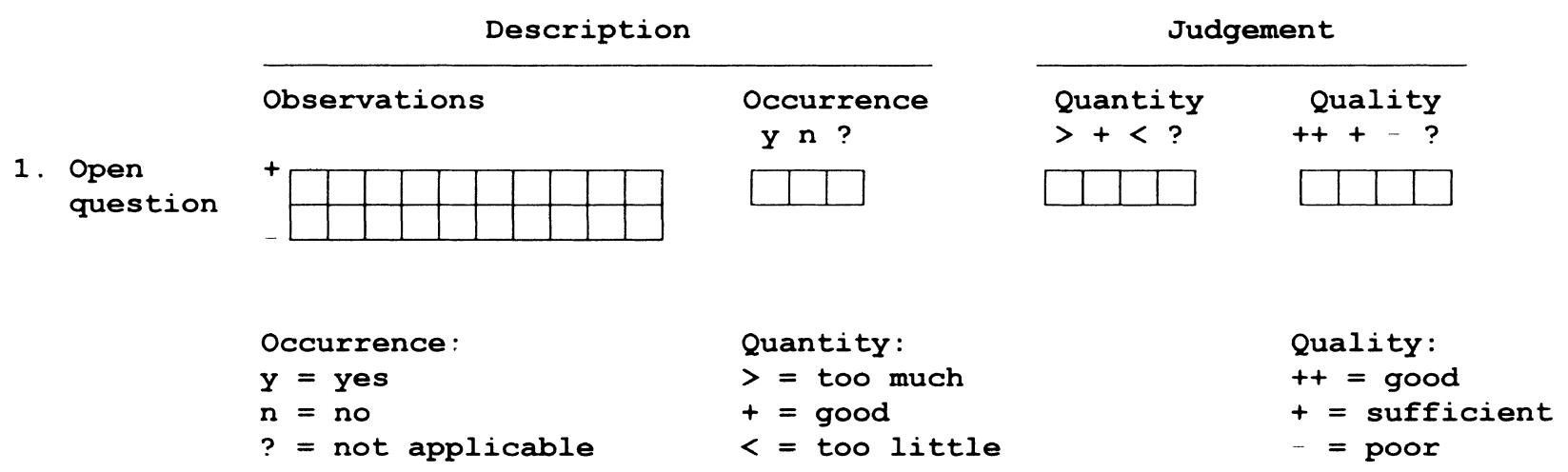

Figure 1 Rating method of the Communication Rating System (CRS).

order; the raters were unaware of which measurement stage each consultation belonged to.

The CRS proved to be a reliable instrument. The inter-rater reliability was tested in 24 consultations which were rated independently by 2 raters. The average percentage agreement of the frequency ratings is $91 \%$ (range: $75 \%$ to $100 \%$ ), of the quantity judgements $95 \%$ (range: $83 \%$ to $100 \%$ ) and of the quality judgements $79 \%$ (range: $58 \%$ to $96 \%$ ). The computation of a percentage of agreement was preferred over the computation of Cohen's Kappa coefficient, which does correct for chance agreement but is highly sensitive to the skewness of the frequency distribution. ${ }^{24,25}$ With regard to the general rating, the Pearson intercorrelation is $0.75(P<0.001)$.

Source 2: The patient satisfaction about the interaction with their physicians was measured by means of the Medical Interview Satisfaction Scale (MISS). ${ }^{26} \mathrm{~A}$ Dutch translation was made using the backward and forward translation method. The MISS measures cognitive (physician's explanations, patient's understanding), affective (patient's perception of the interpersonal relationship) and behavioural (physician's professional behaviour, physical examination) aspects of the interaction. All items are rated on five-point Likert-type scales with labels ranging from 'strongly agree' to 'strongly disagree'.

\section{Analysis}

A specific characteristic of the data-set in this study is that it consists of two levels; the level of the patient or the consultation, and the level of the physician. The observations at the consultation level are explained by an intervention at the physician level. Since each physician is doing several consultations, the behavioural observations cannot be regarded as statistically independent. Patients of a particular physician can be expected to be treated more similarly than patients of different physicians. ${ }^{27}$

Both problems, difference in level of intervention and measurement and the problem of dependency in the data, are dealt with by applying multilevel analysis. ${ }^{28}$ In multilevel analysis (MLA) the variance of the dependent variable is divided into a component that is related to differences between groups (consultations of different physicians) and a component related to differences within groups (between consultations of the same physician).

Three models were of specific interest to test the effect of the CAI intervention on the physician communication behaviour and patient satisfaction. In the first model, the mean score before training ( $\mathrm{T} 1$ and $\mathrm{T} 2$ ) is compared to the mean score after training (T3 and T4). The fit of this model is compared to the fit of a null model without independent variables. In the second model each measuring stage is entered separately. Comparison of the fit of model 2 with the fit of model 1 tests whether there are additional differences between individual measuring stages. In the third model implementers are distinguished from non-implementers. An improved fit of model 3 provides information about whether the effects are differential for implementers and non-implementers. All analyses were performed with the MLn software. ${ }^{29}$

\section{Hypotheses}

After the course, the participating physicians are expected to display more patient-centred behaviour, reflected in a higher general rating and higher average quality rating of their behaviour as well as a better judgement of the average quantities of behaviour. Improvements are expected to occur in the intervention period, between T2 and T3. No differences are expected in the control period between $\mathrm{T} 1$ and $\mathrm{T} 2$, and in the follow-up period between T3 and T4. The same effects 
are expected for the patient satisfaction ratings. Patient satisfaction is expected to be positively related to the communication behaviour of the physician. The described course effects on physician behaviour and patient satisfaction are particularly expected among the implementing physicians, whereas they are considered less likely to occur among the non-implementers.

\section{Results}

\section{Source 1: behavioural assessment}

Analyses of the CRS descriptive ratings revealed no course effect on the frequencies of the communication behaviours. Course effects were found on several judgement ratings which will be presented here. Table 2 shows the weighted average judgement ratings per measuring moment for all physicians and for implementers and non-implementers separately.

The mean general rating of the physicians' communication behaviour is $7 \cdot 4$, indicating that on average the behaviour is of a sufficient quality, but still there is room for improvement towards a good or excellent level. Table 2 shows that the average quality of the communication behaviours is rated quite high. Whereas the scores can range between 1 (poor) and 3 (good), at each measurement most quality ratings are above $2 \cdot 5$. The average quantity ratings indicate that, overall, approximately $10 \%$ of the 23 observation categories were used too little or too often (both rated as poor).

Multilevel analysis of the first model, comparing the combined post-course ratings to the combined precourse ratings, shows training effects on the general rating (difference in fit between null model and model 1: $\chi^{2}=10.7$ d.f. $\left.=1 ; P=0.001\right)$, the average quality rating $\left(\chi^{2}=4.9 ;\right.$ d.f. $\left.=1 ; P=0.027\right)$ and on the average quantity rating $\left(\chi^{2}=4 \cdot 4\right.$; d.f. $\left.=1 ; P=0.043\right)$.

The second model, testing for additional changes between individual measuring moments, yields better fit for the general rating only $\left(\chi^{2}=7 \cdot 0\right.$; d.f. $=2$; $P=0.030$ ). Inspection of the means reveals that this effect can be attributed to a difference between $\mathrm{T} 2$ and the other measuring stages. Model 2 did not show a better fit for the average quality rating $\left(\chi^{2}=1 \cdot 3\right.$; d.f. $=2 ; P=0.522)$ and for the average quantity rating $\left(\chi^{2}=1 \cdot 1 ;\right.$ d.f. $\left.=2 ; P=0.577\right)$.

Analysis of the third model, introducing an additional model parameter for implementers and nonimplementers, shows a better fit than model 1 for two variables. Significant interaction effects were found on the average quality rating $\left(\chi^{2}=6.2 ;\right.$ d.f. $=2$;

\begin{tabular}{|c|c|c|c|c|}
\hline & $\mathrm{T} 1$ & $\mathrm{~T} 2$ & T3 & $\mathrm{T} 4$ \\
\hline \multicolumn{5}{|l|}{ General rating $^{\mathrm{a}}$} \\
\hline all physicians & $7 \cdot 39(\cdot 16)$ & $7 \cdot 06(\cdot 16)$ & $7 \cdot 58(\cdot 16)$ & $7 \cdot 49(\cdot 16)$ \\
\hline implementers & $7 \cdot 45(\cdot 26)$ & $7 \cdot 29(\cdot 25)$ & $7 \cdot 81(\cdot 26)$ & $7 \cdot 75(\cdot 25)$ \\
\hline non-implementers & $7 \cdot 36(\cdot 20)$ & $6.92(\cdot 20)$ & $7 \cdot 44(\cdot 20)$ & $7 \cdot 33(\cdot 20)$ \\
\hline \multicolumn{5}{|c|}{ Average quantity rating $(\% \text { good })^{\mathrm{b}}$} \\
\hline all physicians & $89 \cdot 7 \%$ & $88 \cdot 2 \%$ & $90 \cdot 9 \%$ & $91 \cdot 6 \%$ \\
\hline implementers & $88 \cdot 5 \%$ & $88 \cdot 9 \%$ & $93 \cdot 4 \%$ & $96 \cdot 0 \%$ \\
\hline non-implementers & $90 \cdot 5 \%$ & $87 \cdot 9 \%$ & $89 \cdot 5 \%$ & $88 \cdot 9 \%$ \\
\hline \multicolumn{5}{|c|}{ Average quality rating $(1=\text { poor, } 3=\text { good })^{\mathrm{c}}$} \\
\hline all physicians & $2.59(\cdot 04)$ & $2.55(\cdot 04)$ & $2 \cdot 64(\cdot 04)$ & $2 \cdot 62(\cdot 04)$ \\
\hline implementers & $2.59(\cdot 07)$ & $2 \cdot 62(\cdot 07)$ & $2 \cdot 71(\cdot 07)$ & $2 \cdot 75(\cdot 07)$ \\
\hline non-implementers & $2 \cdot 60(\cdot 05)$ & $2 \cdot 51(\cdot 05)$ & $2.59(\cdot 05)$ & $2 \cdot 55(\cdot 05)$ \\
\hline \multicolumn{5}{|c|}{ Nonverbal quality rating $(1=\text { poor, } 3=\text { good })^{\mathrm{d}}$} \\
\hline all physicians & $2 \cdot 32(\cdot 12)$ & $2 \cdot 27(\cdot 12)$ & $2 \cdot 36(\cdot 12)$ & $2 \cdot 39(\cdot 12)$ \\
\hline implementers & $2 \cdot 25(\cdot 19)$ & $2 \cdot 22(\cdot 19)$ & $2 \cdot 47(\cdot 19)$ & $2 \cdot 63(\cdot 19)$ \\
\hline non-implementers & $2 \cdot 36(\cdot 15)$ & $2 \cdot 30(\cdot 15)$ & $2 \cdot 30(\cdot 15)$ & $2 \cdot 25(\cdot 15)$ \\
\hline \multicolumn{5}{|c|}{ 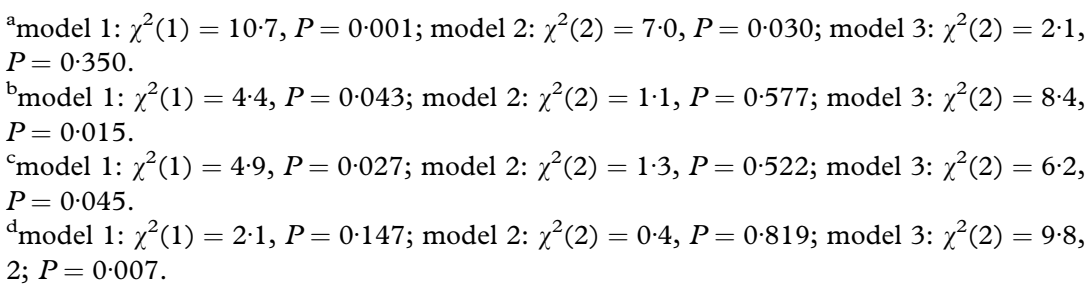 } \\
\hline
\end{tabular}

Table 2 Weighted mean judgement ratings of communication behaviour (standard errors) 

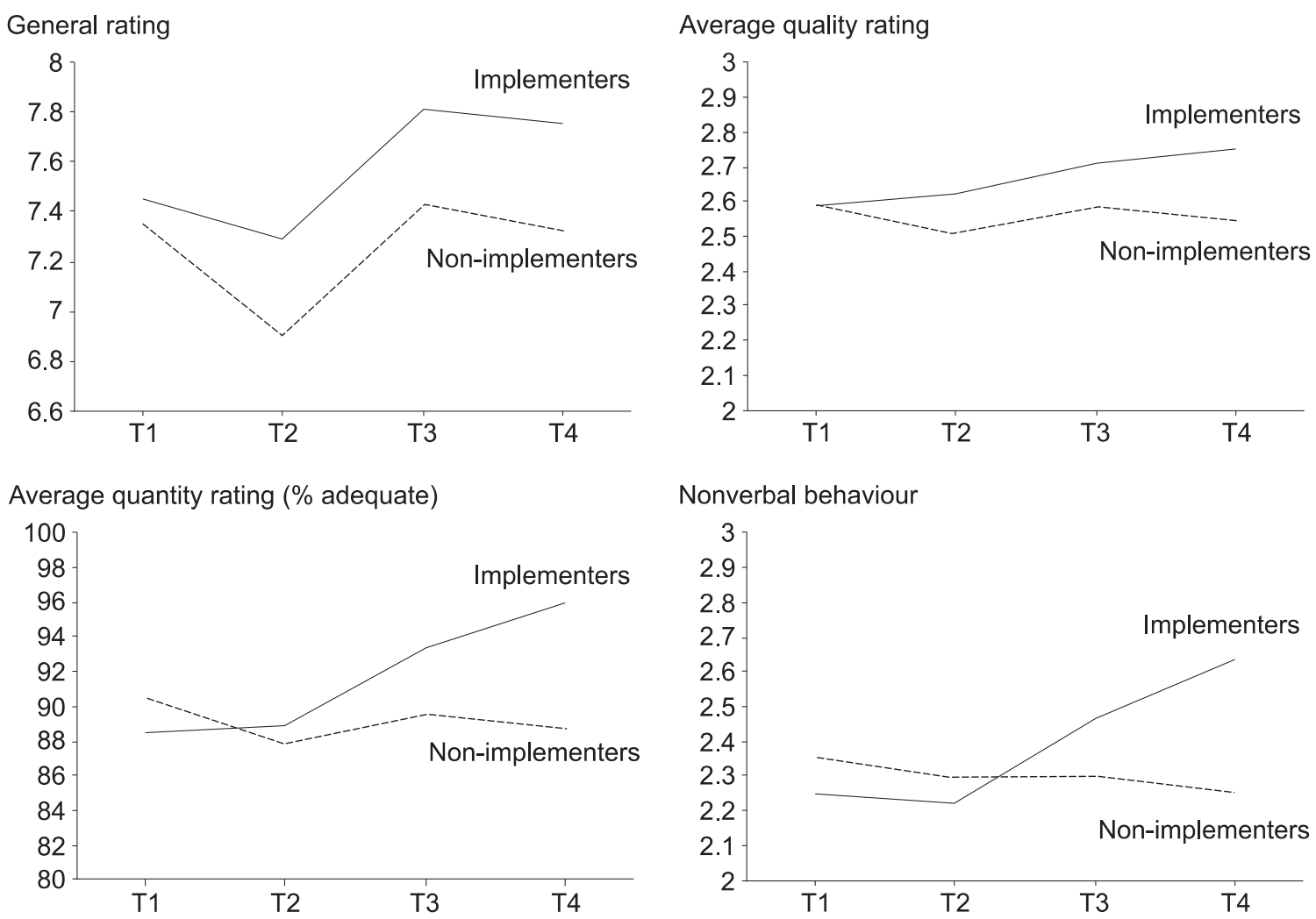

Figure 2 Variables with differential course effects in implementing and non-implementing physicians.

$P=0.045)$ and on the average quantity rating $\left(\chi^{2}=8 \cdot 4\right.$; d.f. $\left.=2 ; P=0 \cdot 015\right)$. These results are due to post-course improvements for implementers, whereas the non-implementers showed no improvements. Model 3 did not provide a significantly better fit for the general rating $\left(\chi^{2}=2 \cdot 1\right.$; d.f. $\left.=2 ; P=0.350\right)$.

Analyses of the seven individual subscales of the CRS did not reveal significant results, except for the nonverbal quality rating which showed a significant better fit of model 3 compared to model $1\left(\chi^{2}=9 \cdot 8\right.$; d.f. $=2$; $P=0 \cdot 007)$. A training effect was found for implementers, but not for non-implementers.

In conclusion, course effects mainly applied to the 'implementing' physicians, whereas the 'non-implementers' showed no post-course improvements. On the general rating course effects were found for both physician groups. This differential course effect on the behavioural assessment is illustrated in Fig. 2 .

\section{Source 2: patient satisfaction}

The weighted average satisfaction ratings of the patients per measuring stage are displayed in Table 3. As expected, the patients were on average quite satisfied about the interaction with their physician. On all sub- scales, ranging from 1 to 5 , the average ratings are above 4 .

In a multilevel analysis of the first model no better fit than the null model was found on any of the satisfaction scales of the MISS. This indicated that post-training patients were not more satisfied than the pre-training patients. The second model did not show a significantly better fit either. This means that on the satisfaction scales no significant differences exist between the four measuring moments. This is true for both implementers and non-implementers, as model 3 did not show a significantly better fit. So, no training effects were found on the patient satisfaction about their physician's communication behaviour.

Since the patient satisfaction ratings are assumed to reflect the quality of the interaction, they are expected to be correlated with the CRS general rating and the average quality rating of the physician behaviour. Contrary to our expectations these correlation coefficients were not statistically significant.

\section{Discussion}

The main research question can be answered as cautiously affirmative. Independent assessment of the 


\begin{tabular}{|c|c|c|c|c|}
\hline & $\mathrm{T} 1$ & $\mathrm{~T} 2$ & $\mathrm{~T} 3$ & $\mathrm{~T} 4$ \\
\hline \multicolumn{5}{|c|}{$(1=$ low, $5=$ high satisfaction $)$} \\
\hline Total (all items) & $4 \cdot 08(\cdot 07)$ & $4 \cdot 26(\cdot 07)$ & $4 \cdot 16(\cdot 07)$ & $4 \cdot 26(\cdot 07)$ \\
\hline implementers & $4 \cdot 15(\cdot 13)$ & $4 \cdot 22(\cdot 12)$ & $4 \cdot 13(\cdot 12)$ & $4 \cdot 37(\cdot 11)$ \\
\hline non-implementers & $4 \cdot 04(\cdot 09)$ & $4 \cdot 28(\cdot 09)$ & $4 \cdot 18(\cdot 09)$ & $4 \cdot 19(\cdot 09)$ \\
\hline Cognitive scale & $4 \cdot 00(\cdot 09)$ & $4 \cdot 21(\cdot 08)$ & $4 \cdot 10(\cdot 08)$ & $4 \cdot 21(\cdot 08)$ \\
\hline implementers & $4 \cdot 13(\cdot 14)$ & $4 \cdot 22(\cdot 14)$ & $4 \cdot 09(\cdot 14)$ & $4 \cdot 30(\cdot 13)$ \\
\hline non-implementers & $3.94(\cdot 11)$ & $4 \cdot 20(\cdot 11)$ & $4 \cdot 11(\cdot 11)$ & $4 \cdot 16(\cdot 10)$ \\
\hline Affective scale & $4 \cdot 24(\cdot 08)$ & $4 \cdot 37(\cdot 08)$ & $4 \cdot 24(\cdot 08)$ & $4 \cdot 37(\cdot 08)$ \\
\hline implementers & $4 \cdot 27(\cdot 14)$ & $4 \cdot 37(\cdot 13)$ & $4 \cdot 20(\cdot 14)$ & $4.52(\cdot 13)$ \\
\hline non-implementers & $4 \cdot 21(\cdot 10)$ & $4 \cdot 38(\cdot 10)$ & $4 \cdot 25(\cdot 10)$ & $4 \cdot 29(\cdot 10)$ \\
\hline Behavioural scale & $4 \cdot 08(\cdot 07)$ & $4 \cdot 27(\cdot 06)$ & $4 \cdot 17(\cdot 07)$ & $4 \cdot 26(\cdot 06)$ \\
\hline implementers & $4 \cdot 15(\cdot 11)$ & $4 \cdot 24(\cdot 10)$ & $4 \cdot 11(\cdot 11)$ & $4 \cdot 27(\cdot 10)$ \\
\hline non-implementers & $4 \cdot 05(\cdot 08)$ & $4 \cdot 29(\cdot 08)$ & $4 \cdot 20(\cdot 08)$ & $4 \cdot 26(\cdot 08)$ \\
\hline
\end{tabular}

Table 3 Weighted mean patient satisfaction ratings (standard errors) communication behaviour of medical specialists lead to the conclusion that a computer-assisted instruction programme indeed can induce some changes in their communication behaviour. Even a relatively brief course, which could be completed within four hours, could effect improvements in the performance of communication behaviour of a group of initially wellperforming physicians. The second research question could not be confirmed. Contrary to expectations, no course effects were found on the patient satisfaction ratings and patient satisfaction did not correlate with the independent assessment of the physicians' behaviour.

Improvements in communication behaviour were found in particular among physicians who intentionally put the skills taught into practice. This differentiated result between implementers and non-implementers implies that the participants' motivation to change is an important precondition in being able to realize changes in their communication behaviour. However, more research is needed into how the physicians' motivation to change can be strengthened. In a study on the motives of general practitioners to attend to postgraduate education, less than $50 \%$ of the respondents indicated that they intended to use the information gained to change their behaviour. ${ }^{30}$ In our study, only 8 of the 21 physicians (38\%) indicated after the course that they were putting some of the skills taught into practice. Additional strategies are needed to effectuate the implementation of newly acquired skills. The readiness of physicians to change their working style may be affected by a change of the prevailing scientific model in medicine. ${ }^{1}$ Particularly among medical specialists the biomedical model is still prevailing; diseases are treated primarily as a somatic problem. Strategies which encourage adoption of a biopsycho- social model may facilitate the use of patient-centred communication. ${ }^{4}$

In this study, course effects were found on overall judgement ratings of the quantity and quality of behaviour, and not on the frequencies of communication behaviours. The application of judgement ratings in this study deviates from many other evaluation studies which generally use only frequency counts. ${ }^{10}$ Frequency measures have limitations. ${ }^{23}$ Firstly, they do not take into account how the communication behaviours are performed. For example, ratings of how frequently information behaviours occurred in an encounter do not provide insight into the clarity of the information and whether it addressed the patient's needs. Secondly, the frequencies of communication behaviours may not only be determined by the style of the physician, but also by patient characteristics or the context of the interaction. The physicians' communication behaviour is responsive to the patients' requirements. ${ }^{31}$ The frequencies of behaviours the physicians display will differ accordingly. These encounter-specific effects on the physicians' frequencies of behaviour may interfere with establishing course effects. To get around these limitations of frequency-based ratings, global judgement ratings were added to each observation category of the CRS. However, it is wrong to assume that global ratings can fully replace the systematic observation of communication behaviours. After all, the judgement ratings were assigned after a detailed analysis of the occurrence of distinctive behaviours in the interaction had been performed.

Satisfaction is the most recognized and widely used outcome measure in research of medical communication. ${ }^{2,3}$ In this study, patients' satisfaction with their physicians' communication behaviour was measured as additional source of information about the effectiveness 
of 'Interact-Cancer'. Several explanations may apply to the lack of results on this outcome measure.

First, the absence of course effects on the patients' satisfaction ratings suggest that the improvement in the physicians' communication behaviour may be too small to be detected by the patients. The fact that the initial performance level of the physicians was relatively high may contribute to this idea. Second, a lack of correlations between patient satisfaction and independent assessment of the physician's behaviour suggests that patients focus on different aspects of the communication than the CRS ratings do. Whereas the independent assessments focus primarily on the performance of behaviours, basically the content of the communication is of personal interest to patients. When the content of the communication presumably has not changed as a result of the course, patient satisfaction has not either. Furthermore, in our study only follow-up consultations where analyzed. This implies that patient satisfaction ratings may not only reflect the physician's performance in the particular consultation, but also the patient's general opinion about the physician, based on previous encounters. ${ }^{32}$ This phenomenon may reduce the magnitude of the correlations between the independent and patient ratings of the physician's behaviour. Finally, the patients' possible awareness of improvements in the physicians' behaviour could perhaps not be measured due to the fact that the satisfaction ratings are highly positively skewed. The resulting 'ceiling effect' limits the possibility of measuring enhancement of satisfaction levels. In fact, high levels of patient satisfaction are a common finding in many studies. ${ }^{3,6}$ High satisfaction ratings may be explained by a positive bias that patients may have when rating their care to reduce cognitive dissonance, because patients are dependent on their physician and cannot easily choose another. ${ }^{32}$

The limitations of this study relate to the quasiexperimental study design and the selection of medical specialists and patients. Use of a control period was preferred over a separate control group in this study. When using a control group design, random assignment of participants to one of both conditions could be realized within or across locations, which both have some disadvantages. Two groups within a location has a risk of contamination; participants of both groups may meet each other and talk things over. Participants of the control group may even, out of curiosity, take a look at the course. A solution for this is to keep all participants of one location in the same condition and assign the locations randomly to one of both research groups. However, cultural differences between locations may affect the interactions with patients. Further, participants were recruited from various disciplines, making the composition of groups very different per location. Both aspects can make the research groups incomparable which interferes with conclusions about the effectiveness of the course.

Physicians participated in this study on a voluntary basis which may have introduced a selection bias, limiting the generalizability of the study results. The physicians who entered the study, and even more those who completed it, may represent a relatively interested, motivated and initially well performing sample. Selection bias towards highly motivated physicians may have enhanced the effectiveness of 'Interact-Cancer'. Selection bias towards relatively well performing physicians may have limited the effectiveness, due to a ceiling effect. Future research may benefit from random inclusion of participants.

CAI may be particularly attractive for those physicians who feel insecure about the quality of their performance of communication skills. For them, participation in conventional group courses may be an unpleasant experience, since they have to display their skills towards an audience of colleagues, simulated patients and trainers. Because of the individualized learning CAI offers, participants can learn about communication skills in a safe, non-threatening learning environment. ${ }^{14}$ CAI provides the learner opportunities to explore the domain without exposure to criticism. For some physicians this may reduce their resistance to participation.

In conclusion, CAI is a promising method to provide practising physicians continuous medical education in the area of communication skills. Adequate performance is the result of a dynamic process of acquiring new knowledge and skills and integrating these in the existing expertise. This cyclical process assumes repeated learning efforts. CAI education may help to provide practising physicians frequent opportunities of learning to refresh knowledge and skills.

\section{Contributors}

RLH was the principal investigator who designed the CAI programme 'Interact-Cancer', collected and analyzed the data, and wrote the manuscript. WJGR and JAMW jointly designed the study. WJGR, JAMW and JMB supervised the research activities and contributed to the interpretation of the results. All authors reviewed the paper.

\section{Acknowledgements}

This study was granted by the Dutch Cancer Society, the Nijbakker Morra Foundation, and the Nijenburgh 
Foundation. The authors thank J.J. Kerssens and P. Spreeuwenberg of the NIVEL and F.J. Oort of the Academic Medical Centre Amsterdam for their kind assistance on the multilevel statistical analyses.

\section{References}

1 Smith RC, Hoppe RB. The patient's story. Integrating the patient- and physician-centered approaches to interviewing. Ann Intern Med 1991;115:470-7.

2 Smith RC, Lyles JS, Mettler J, Stoffelmayr BE, Van Egeren LF et al. The effectiveness of intensive training for residents in interviewing. A randomized, controlled study. Ann Intern Med 1998;128:118-26.

3 Brown JB, Boles M, Mullooly JP, Levinson W. Effect of clinician communication skills training on patient satisfaction. A randomized controlled trial. Ann Intern Med 1999;131: $822-9$.

4 Stewart MA, Brown JB, Weston WW, McWhinney IR, McWilliam CL, Freeman TR, eds. Patient-Centered Medicine. Transforming the Clinical Method. London: Sage; 1995.

5 Ford S, Fallowfield L, Lewis S. Doctor-patient interactions in oncology. Social Sci Med 1996;42:1511-9.

6 Winefield H, Murrell T, Clifford J, Farmer E. The search for reliable and valid measures of patient-centredness. Psychol Health 1996;11:811-24.

7 Whitehouse CR. The teaching of communication skills in United Kingdom medical schools. Med Educ 1991;25:311-8.

8 Batelaan MA. Inventarisatie onderwijs communicatievaardigheden faculteiten geneeskunde. [Survey of Communication Skills Training in the Dutch Medical Schools]. Amsterdam: Free University, Faculty of Medicine. Department of Medical Psychology; 1995.

9 Moorhead R, Winefield $\mathrm{H}$. Teaching counselling skills to fourth-year medical students: a dilemma concerning goals. Family Prac 1991;8:343-6.

10 Roter DL, Hall JA, Kern DE, Barker R, Cole KA, Roca RP. Improving physicians' interviewing skills and reducing patients' emotional distress. Arch Intern Med 1995;155:1877-84.

11 Cohen PA, Dacanay LS. Computer-based instruction and health professions education: a meta-analysis of outcomes. Evaluation Health Professions 1992;15:259-81.

12 Garrud P, Chapman IR, Gordon SA, Herbert M. Non-verbal communication: evaluation of a computer-assisted learning package. Med Educ 1993;27:474-8.

13 Hannafin MJ, Peck KL. The Design, Development and Evaluation of Instructional Software. New York: MacMillan; 1988.

14 Seabury BA, Maple FF. Using computers to teach practice skills. Social Work 1993;38:430-9.

$15 \mathrm{McNeil}$ BJ, Nelson KR. Meta-analysis of interactive video instruction: a 10 year review of achievement effects. $\mathcal{F}$ Computer-Based Instruction 1991;18:1-6.

16 Droste-Bielak EM. Two techniques for teaching interviewing. Computers Nursing 1986;4:152-7.
17 Poulin JE, Walter CA. Interviewing skills and computerassisted instruction: BSW student perceptions. Computers Human Services 1990;7:179-97.

18 Napholz L, McCanse R. Interactive video instruction increases efficiency in cognitive learning in a baccalaureate nursing education program. Computers Nursing 1994;12:149-53.

19 Francke AL, Garssen B, Huijer Abu-Saad H. Determinants of changes in nurses' behaviour after continuing education: a literature review. F Advanced Nursing 1995;21:371-7.

20 Hulsman RL, Ros WJG, Janssen M, Winnubst JAM, InteractCancer. The development and evaluation of a computerassisted course on communication skills for medical specialists in oncology. Patient Education Counseling 1997;30:129-41.

21 Hulsman RL, Janssen M, Ros WJG. Handleiding Scoreformulier Video-Opnamen. [Manual of the Communication Rating System]. Utrecht: Utrecht University Faculty of Medicine; 1994.

22 Pieters HM. De Utrechtse Consult Evaluatie Methode. Vaardigheden in consultvoering van huisartsen in opleiding getoetst. [The Utrecht Consultation Assessment Method. The assessment of consultation skills of trainees in the vocational training]. Lelystad: Dissertation, University Utrecht. MEDITekst; 1991.

23 Inui TS, Carter WB. Problems and prospects for health services research on provider-patient communication. Med Care 1985;23:521-38.

24 Cohen J. A coefficient of agreement for nominal scales. Educational Psychol Measurement 1960;20:37-46.

25 Triet EF, Dekker J, Kerssens JJ, Curfs EC. Reliability of the assessment of impairments and disabilities in survey research in the field of physical therapy. Int Disability Studies 1990;12:61-5.

26 Wolf MH, Putnam SM, James SA, Stiles WB. The medical interview satisfaction scale: Development of a scale to measure patient perceptions of physician behavior. $\mathcal{F}$ Behav Med 1978;1:391-401.

27 Bensing JM, Kerssens JJ, van der Pasch M, . Patient-directed gaze as a tool for discovering and handling psychosocial problems in general practice. $\mathcal{F}$ Nonverbal Behav 1995;19:223-42.

28 Goldstein H. Multi-Level Statistical Models. New York: Halsted Press; 1995.

29 Rasbash J, Woodhouse G. MLn Command Reference, Version 1.0. Multilevel Models Project. London: Institute of Education. University of London; 1995.

30 Kelly MH, Murray TS. Motivation of general practitioners attending postgraduate education. Br $\mathcal{F}$ General Prac 1996;46:353-6.

31 Stiles WB. Evaluating medical interview process components. Null correlations with outcomes may be misleading. Med Care 1989;27:212-20.

32 Carr-Hill RA. The measurement of patient satisfaction. f Public Health Med 1992;14:236-49.

Received 12 December 2000; editorial comments to authors 13 March 2001; accepted for publication 29 March 2001 